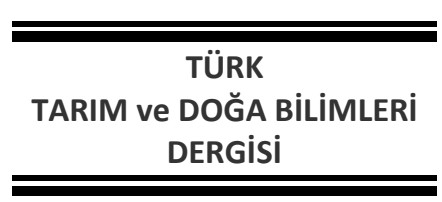

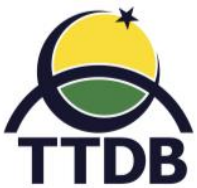

www.dergipark.gov.tr/turkjans

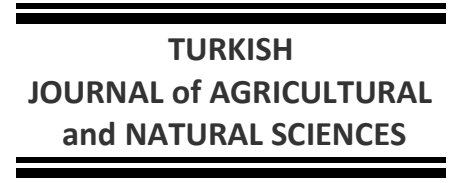

Araştırma Makalesi

\title{
Kendilenmiş Mısır Hatlarının Kuraklık Stresine Tolerans Düzeylerinin Belirlenmesi
}

\author{
Şekip ERDAL*
}

Batı Akdeniz Tarımsal Araştırma Enstitüsü Müdürülüğü-Antalya

*Sorumlu yazar: sekip65@yahoo.com

Geliş Tarihi: 17.08.2018

Düzeltme Geliş Tarihi: 04.12.2018

Kabul Tarihi: 19.02.2019

Özet

Bu çalışmanın amacı, kuraklık stresine toleranslı hibrit çeşitleri geliştirmek için kendilenmiş mısır hatlarını kuraklığa tolerans açısından taramaktır. Çalışmada at dişi ve sert tane tipine sahip 20 adet mısır hattı 2012 ve 2013 yıllarında normal (sulu) ve kuraklık stresi denemelerinde değerlendirilmiştir. Denemeler tesadüf blokları deneme desenine göre 3 tekerrürlü olarak ekilmiştir. Normal denemede mevcut nem tarla kapasitesinde tutulurken, kuraklık stresi denemesinde bitkiler V10-12 gelişme döneminden (takriben çiçeklenme tarihinden 23 hafta önce) itibaren strese maruz bırakılmıştır. Denemelerde kuraklık stresi çalışmalarında en çok öne çıkan seleksiyon kriterleri olan erkek ve dişi çiçek arasındaki gün farkı (EDF), bitki başına koçan sayısı (BBKS), koçanda tane sayısı (KTS), yaprak kuruma düzeyi ve tane verimi özellikleri incelenmiş ve stres indeksleri ile hatlar kuraklığa toleranslııı bakımından karakterize edilmiştir. Araştırma sonucunda, Ant i-69 (229.4kg/da), TK 72 (220.5 kg/da), Ant-24702 (196.4 kg/da), Ant i-39 (174.6 kg/da) ve Ant i-09 (146.8 kg/da) hatları tane verimi bakımından kuraklık stresine en toleranslı hatlar olurken, Ant 910255 (27.6 kg/da), Ant i-46 (28.2 kg/da), Ant i-82 (29.0 kg/da) ve Ant i-08 (45 kg/da) en hassas hatlar olarak tespit edilmişlerdir. Ant i-69, TK 72, Ant-24702, Ant i-39 ve Ant i-09 hatları aynı zamanda EDF, BBKS, KTS ve yaprak kuruma düzeyi ve stres tolerans indeksleri bakımındanda en çok öne çıkan hatlar olmuşlardır. Araştırma sonucunda kullanılan mısır genetik materyalinin kuraklığa tolerans ıslahı için değerlendirilebileceği öngörülmüş ve seçilen mısır hatları gelecek dönem çalışmaları için önerilmiştir.

Anahtar kelimeler: Mısır, kendilenmiş hat, kuraklık stresi, verim.

\section{Determination of Drought Tolerance Levels of Maize Inbred Lines}

\begin{abstract}
The objective of the study was to test maize inbred lines for drought tolerance. In the study twenty dent and flint temperate maize inbred lines were evaluated in well-watered and drought stress conditions in 2012 and 2013. Experiments conducted according to Randomized Complete Block Design with three replications. Drought stress was achived at the flowering by withdrawn water approximately 2-3 weeks before flowering. Anthesissilking interval (ASI), number of ears per plant (EPP), number of kernels per ear (KPE), senescence and yield traits which are used as the most important selection criterions were evaluated. Also stress indices were used for line identification to drought. The result of the study showed that, Ant I-69 (229.4 kg/da), TK 72 (220.5 kg/da), Ant24702 (196.4 kg/da), Ant I-39 (174.6 kg/da) and Ant I-09 (146.8 kg/da) were determined as the most tolerant lines to drought, while Ant 910255 (27.6 kg/da), Ant I-46 (28.2 kg/da), Ant I-82 (29.0 kg/da) and Ant I-08 ( 45 $\mathrm{kg} / \mathrm{da}$ ) inbreds were identified as the sensitive lines in terms of yield. Tolerant promising lines Ant I- 69, TK 72, Ant-24702, Ant I-39 and Ant I-09 were also had good performance in terms of secondary traits such as ASI, number of ears per plant, number of kernel per ear, senescence, yield reduction ratio, drought resistance index and stress tolerance index.In conclusion, it was envisaged that tested maize germplasm can be assessed for breeding drought tolerance and selected maize inbred lines were proposed for future studies.
\end{abstract}

Key words: Maize, inbred line, drought tolerance, yield. 
Giriş

Türkiye küresel ısınmaya bağlı olarak, görülebilecek bir iklim değişikliğinden en fazla etkilenecek ülkelerden birisidir. Türkiye'nin farklı bölgeleri iklim değişikliğinden farklı biçimde ve değişik boyutlarda etkilenmesi beklenmektedir. Sıcaklık artışından daha çok çölleşme tehdidi altında bulunan Güney Doğu ve iç Anadolu gibi, kurak ve yarı kurak bölgelerle, yeterli suya sahip olmayan yarı nemli Ege ve Akdeniz bölgelerinin daha fazla etkileneceği tahmin edilmektedir (Türkeş, 1998). iklim değişikliklerinden tarım ve hayvancılığın önemli düzeyde etkileneceği, özellikle sözkonusu bölgelerde su problemlerinin yaşanacağı belirtilmektedir (Öztürk, 2002). Kuraklık stresi, tüm dünyada mısır verimi ve kalitesini olumsuz şekilde etkileyen en önemli abiotik streslerin başında gelmektedir. Su kaynaklarının azalması ve yüksek sıcaklıkla kombine halinde kuraklık ülkemiz mısır üretimini ve kalitesini olumsuz bir şekilde etkilemektedir. Kuraklık stresi mısır bitkisini her dönemde etkileyebilir. Ekimle birlikte toprakta yeterince nem yoksa düzensiz bitki çıkışları arazide kendini göstermektedir. Çiçeklenme öncesi yaprak alanının gelişmesinin zayıf olması ve fotosentez oranın azalması kuraklığın önemli etkilerindendir. Çiçeklenme ve tane doldurma döneminde erken yaprak kurumaları ve fotosentez oranın azalması ile koçan ve tane sayısında azalma sıklıkla görülen durumlardır. Bitki gelişiminde ve döllenme döneminde kuraklığın şiddeti ve zamanına göre tane verimi ciddi bir şekilde etkilenir (Banziger ve ark. 2000). Ancak, en önemli zarar çiçeklenme döneminde olmaktadır (Denmead ve Shaw, 1960; Classen ve Shaw, 1970; Grant ve ark. 1989; Banziger ve ark. 2000). Mısır bitkisi monoik bir yapıda olup, erkek (tepe püskülü) ve dişi (koçan) çiçekler aynı bitki üzerinde fakat farklı yerlerdedir. Kuraklıkla birlikte koçan gelişimi tepe püskülü gelişimine oranla daha yavaş olmakta ve bu nedenle döllenmede sorunlar meydana gelmektedir (Edmeades ve ark. 2000). Mısırda kuraklıkla mücadelede en etkili yöntemlerden bir tanesi de kuraklığı ya da su stresini tolere edebilecek çeşitlerin ıslah edilmesidir. Kuraklıktan kaçma ya da diğer tarımsal yaklaşımlar yararlı olabilirken üretici açısından tohumdan gelebilecek herhangi bir tolerans daha cezbedicidir. Mısırda kuraklığı tolere edebilen hat veya çeşitlerin ıslah edilmesi kuraklıkla mücadelede başarılı bir yaklaşım olup bu konuda farklı ıslah programları ile birçok çalışma yapılmıştır (Edmeades ve ark. 1997; Ribaut ve ark. 1997a; Baenziger ve ark. 2000; Pandey ve ark. 2000; Viswanatha ve ark. 2002; Karam ve ark. 2003). Bu çalışmalarda tropikal bölgeler hedef alınmış ve daha çok tropikal materyal ile çalışılmıştır. Türkiye gibi ılıman iklim (temperate) kuşağındaki bölgeler için kuraklığa tolerans ıslahına ihtiyaç duyulmaktadır. Kuraklığa tolerans için ıslah materyalinin kuraklık stresi altında test edilmesi ve hassas ile toleranslı olanların ayırt edilmesi önemli bir çalışma konusunu oluşturmaktadır.

Bu çalışmanın amacı kendilenmiş ılıman iklim mısır hatlarının kuraklığa tolerans düzeylerini araştırmak, daha önce kuraklığa nasıl tepki verdikleri bilinmeyen ılıman iklim (temperate) mısır saf hatlarını test ederek gelecek dönem çalışmaları için hassas/tolerant hat veya hatları belirlemektir.

\section{Materyal ve Yöntem}

Araştırmada 20 adet kendilenmiş (saf) mısır hattı bitkisel materyali oluşturmuştur. Saf hatların tamamı sarı at dişi, sert ve orta mısır tiplerinden oluşmuştur.

Denemeler; Antalya koşullarında, Batı Akdeniz Tarımsal Araştırma Enstitüsü, Tarla Bitkileri Bölümü'nün $30^{\circ} 50^{\prime}$ doğu boylamı $36^{\circ} 52^{\prime}$ kuzey enleminde yer alan ve deniz seviyesinden $15 \mathrm{~m}$ yükseklikte olan, damla sulama sistemi kurulmuş 2 numaralı deneme arazisinde yürütülmüştür. Genel olarak topraklar tuzsuz, kireçli ve hafif alkali olarak nitelenebilir. Araştırmanın yürütüldüğü 2012 ile 2013 yıllarının Mayıs, Haziran, Temmuz, Ağustos ve Eylül ayları ile aynı döneme ait uzun yıllar (20042013) iklim verileri Çizelge 1'de özetlenmiştir.

Çizelge 1. 2012, 2013 ve uzun yıllar iklim değerleri

\begin{tabular}{lccccccccc}
\hline \multirow{2}{*}{ Aylar } & \multicolumn{2}{c}{ En yüksek hava sıcaklığı $\left({ }^{\circ} \mathbf{C}\right)$} & \multicolumn{2}{c}{ Ortalama hava sıcaklığı $\left({ }^{\circ} \mathbf{C}\right)$} & \multicolumn{3}{c}{ Yağış $(\mathbf{m m})$} \\
\cline { 2 - 11 } & $\mathbf{2 0 1 2}$ & $\mathbf{2 0 1 3}$ & $\begin{array}{c}\text { Uzun } \\
\text { yıllar }\end{array}$ & $\mathbf{2 0 1 2}$ & $\mathbf{2 0 1 3}$ & $\begin{array}{c}\text { Uzun } \\
\text { yıllar }\end{array}$ & $\mathbf{2 0 1 2}$ & $\mathbf{2 0 1 3}$ & $\begin{array}{c}\text { Uzun } \\
\text { yıllar }\end{array}$ \\
\hline Mayıs & 34.9 & 35.8 & 34.7 & 20.5 & 22.5 & 21.0 & 74 & 56.0 & 49.8 \\
Haziran & 43.2 & 38.8 & 39.7 & 26.0 & 25.4 & 25.9 & 4.0 & 0.0 & 4.2 \\
Temmuz & 43.4 & 39.7 & 41.6 & 29.4 & 28.0 & 28.9 & 0.0 & 16.0 & 3.0 \\
Ağustos & 41.2 & 41.5 & 41.0 & 29.1 & 28.7 & 28.8 & 0.0 & 0.0 & 1.8 \\
Eylül & 39.2 & 40.6 & 38.3 & 25 & 24.7 & 25.1 & 2.0 & 19.0 & 27.0 \\
\hline Ortalama & 40.4 & 39.3 & 39.1 & 26 & 25.9 & 25.9 & - & - & - \\
\hline Toplam & - & - & - & - & - & - & 80 & 91 & 85.8 \\
\hline
\end{tabular}


Çalışmada kuraklık stresi denemesi ve normal deneme olmak üzere 2 adet deneme kurulmuştur. Her iki deneme de tesadüf blokları deneme desenine göre 3 tekrarlamalı olarak yürütülmüştür. Deneme parselleri 2 sıra halinde, sıra arası $70 \mathrm{~cm}$ ve sıra üzeri $20 \mathrm{~cm}$ olacak şekilde tasarlanmıştır. Her iki denemenin arazi koşulları aynı olup denemeler aynı tarlada (BATEM Tarla Bitkileri Bölümü arazisi, 2 numaralı parsel) yan yana kurulmuştur. Kuraklık koşulları ve yönetimi Banziger ve ark. (2000), Bruce ve ark. (2002) ve Das ve ark. (2013)'ne göre yapılmıştır. Kuraklık stresi denemelerinde generatif dönem hedef alınmıştır. $\mathrm{Bu}$ nedenle; kurak ve normal denemeye V10-12 gelişme dönemine (çiçeklenmeden yaklaşık olarak 2-3 hafta önce) kadar eşit şekilde su verilerek bu döneme kadar topraktaki nem düzeyi tarla kapasitesine yükseltilmiştir. Çiçeklenme döneminden 2-3 hafta öncesinden itibaren kuraklık denemesine su verilmemiş ve kuraklık tüm generatif gelişme dönemi boyunca sağlanmıştır. Ancak, şiddetli kuraklık koşulları altında tane doldurmayı sağlamak için kuraklık denemesinde, çiçeklenme döneminden sonra Banziger ve ark. (2000)'e göre uygulama sırasında her iki yılda da 1 kez ek sulama yapılmıştır. Araştırma süresince normal ve kuraklık denemelerine verilen sulama suyu miktarları sırasıyla 436.1 ve $266.3 \mathrm{~mm}$ olmuştur. Denemelerin yürütüldüğü 2012 ve 2013 yıllarına ait 0-90 cm toprak profilindeki nem düzeyi Şekil 1'de verilmiştir. Her iki yılda da stres eğrisinin yükselmesinin nedeni planlandığı şekilde yapılan ek sulamalardır.
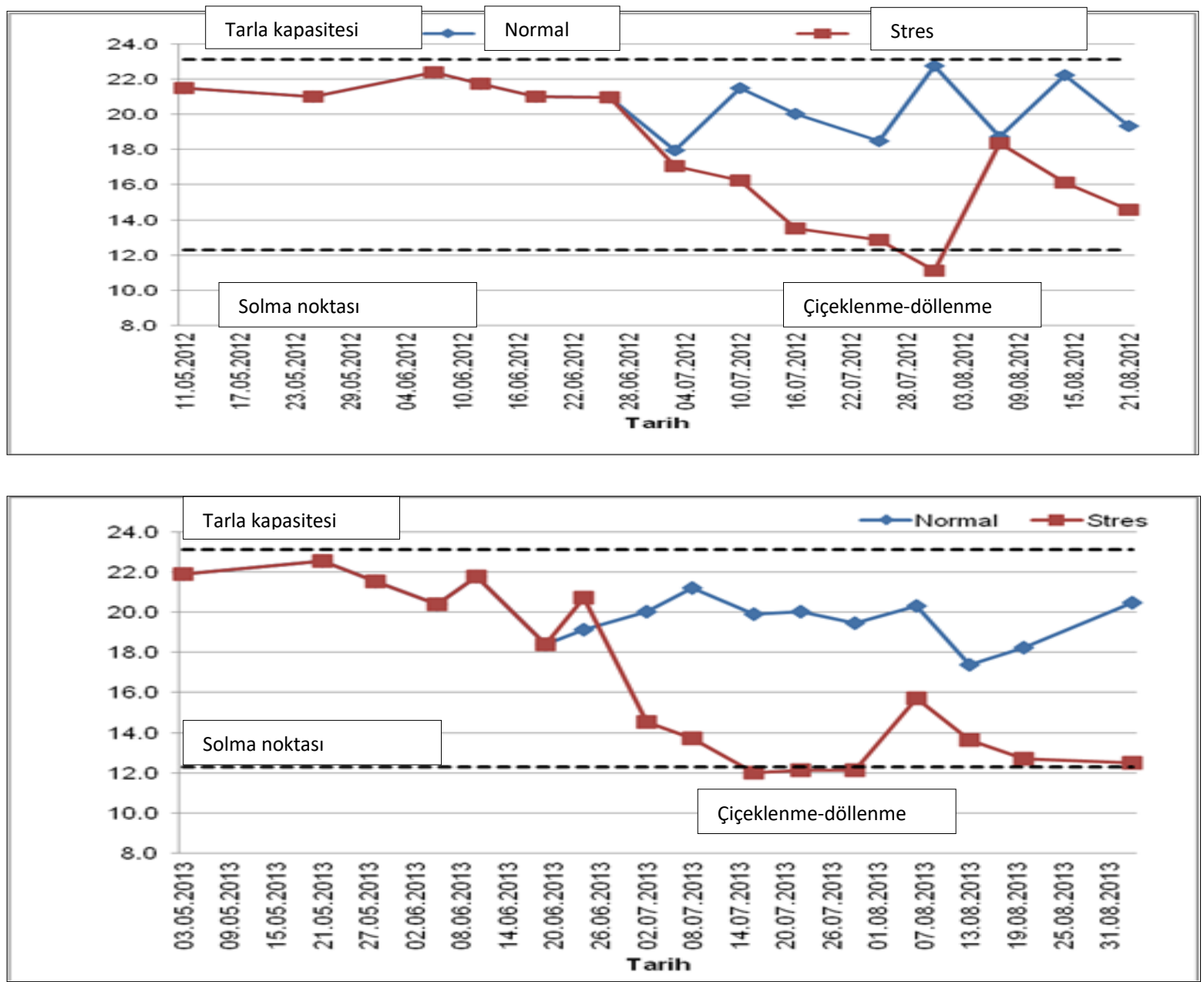

Şekil 1. 2012 (üstte) ve 2013 yılı (altta) 0-90 cm toprak profilindeki nem içeriğinin (\%) değişimi.

Topraktaki nem düzeyi gravimetrik örnekleme yöntemi ile takip edilmiştir. Yöntemde, her sulmadan önce, önceden yerleri belirlenen farklı noktalardan toprak burgusu yardımı ile 0-30, 30-60 ve $60-90 \mathrm{~cm}$ derinliklerden alınan bozulmuş toprak örnekleri daraları alınmış toprak kaplarına konularak labaratuara taşınmıştır. Labaratuarda yaş ağırlıkları belirlenen örnekler etüvde $105{ }^{\circ} \mathrm{C}$ 'de 24 saat bekletilmiş ve tekrar tartılmıştır (Akgöl, 2012). Her iki deneme de dekara saf madde üzerinden 20 $\mathrm{kg}$ azot, $8 \mathrm{~kg}$ fosfor ve $8 \mathrm{~kg}$ potasyum olacak şekilde gübre verilmiştir (Kırtok, 1998). Azotlu gübrenin yarısı taban gübresi olarak verilirken geriye kalan diğer kısmı ise damla sulama ile 2 kez olmak üzere 
1. ara çapa sonrası ve su kesim tarihinden önceki son su ile bitkilere verilmiştir. Yabancı ot kontrolü için elle ve mekanik olmak üzere çapalama işlemi tekrarlanmıştır. Arazide her hafta düzenli zararlı hastalık takibi yapılmış ve gerekli hallerde yeşil kurt, mısır koçan kurdu, sap kurdu, ve afitlere karşı kimyasal ilaçlama yapılmıştır. Araştırmada değerlendirilen özellikler Banziger ve ark. (2000) ile UPOV (2009)'a göre ölçülmüştür. Buna göre, erkek ve dişi çiçek arasındaki gün farkı (EDF), erkek çiçeklenme gün sayısının dişi çiçeklenme gün sayısından çıkartılması ile hesaplanmıştır. Hasat sırasında her parselden elde edilen toplam koçan sayısı parselde bulunan toplam bitki sayısına bölünerek bitki başına koçan sayısı (BBKS) elde edilmiştir. Her parselden rastgele seçilen 5 adet koçan tanelendikten sonra toplam tane sayısı koçan sayısına bölünerek koçanda tane sayısı (KTS) hesaplanmıştır. Yaprak kuruma düzeyi özelliği için, koçan püskülü çıkışından 20 gün ve 30 gün sonra olmak üzere iki kez parseldeki bitki sayısına göre toplam yaprak alanında meydana gelen kuruma gözlemleri 1-10 skalasına göre belirlenmiştir. Skala değerleri :1=\% 10, 2=\%20, 3=\%30, 4=\%40, 5=\%50, $6=\% 60,7=\% 70,8=\% 80,9=\% 90,10=\% 100$ ölü yaprak alanı (\%). Her parselde bulunan koçanlar hasat edilerek tartıldıktan sonra elde edilen parsel ağırlığı, aşağıdaki formül yardımıyla parsel verimine (PV) dönüştürülmüştür. Elde edilen parsel verimi dekara çevirilerek tane verimi $(\mathrm{kg} / \mathrm{da})$ elde edilmiştir.

PV= Parsel Ağırlığı $(g) \times[(100-\%$ Nem $) / 85) \times$ ((Tane/Koçan Oranı)/100]

Kuraklığa dayanıklılık indeksi (KDi) Lan (1998), stres tolerans indeksi Fernandez (1992) ve verim azalış oranı (VAO) Golestani ve Assad (1998)'a göre hesaplanmıştır. İndeksler aşağıda verilen formül yardımıyla hesaplanmıştır.

$\mathrm{KDi}=\mathrm{TVk} \times(\mathrm{TVk} / \mathrm{TVn}) / \mathrm{Tvko}$

$\mathrm{STi}=(T V n / T V n o)(T V k / T V k o)(T V k o / T V n o)$, VAO = $1-($ TVko/TVno $)$,

Eşitlikte,

TVk: Bir genotipin kuraklık stresi koşullarındaki tane verimi,

TVn: Bir genotipin normal koşullardaki tane verimi,

TVko: Kuraklık stresine ait tane verimi deneme ortalaması,

TVno: Normal koşullarda yapılan denemede tane verimine ait deneme ortalaması,

Araştırmada 2 yıllık veriler birleştirilerek varyans analizine (ANOVA) tabi tutulmuştur
(Chocran ve Cox 1957; Peterson, 1994). Hat x yıl interaksiyonu önemli (0.01 ve 0.05$)$ çıkan özelliklerde veriler, yıllar itibariyle değerlendirilmiştir.

\section{Bulgular ve Tartışma}

Normal (sulu) ve kuraklık denemelerine ait erkek ve dişi çiçeklenme aralığına (EDF) ilişkin analiz sonuçları Çizelge 2'de sunulmuştur. Buna göre; 2012 yılında normal denemede EDF 0 (aynı gün çiçeklenmiş) ile 4 gün arasında değişmiştir. Ant i- 09 hattı aynı gün içerisinde hem tepe püskülü ve hem de koçan püskülü çıkaran hat olmuştur. 2013 yılında normal koşullarda EDF 0 ile 3 gün arasında değişirken, en düşük EDF değerleri Ant-24702 ve Ant i-47 hatlarından elde edilmiştir. 2012 yılında kuraklık denemesinde EDF 0 ile 9 gün arasında değişmiş ve en düşük EDF değerini veren hat Ant i09 olmuştur. En yüksek EDF sonuçları ise Ant -08 ve Ant i-84 hatlarında saptanmıştır. 2013 yılında EDF 0 (Ant i-69) ile 8 (Ant 910255) gün arasında değişmiştir. Kuraklık stresi durumunda mısırda koçan püskülü çıkışı gecikmekte ve döllenme için hazır hale gelme süresi uzamaktadır. Hatta bazen hiç püskül çıkmayabilmektedir. Bu durumda, aynı bitki üzerinde yer alan erkek ve dişi çiçek arasında döllenme için senkrinizasyon bozulmakta ve döllenme az ya da hiç gerçekleşememektedir. Kuraklık stresi koşullarında yüksek kalıtım derecesi ve tane verimi ile olan önemli korelasyon düzeyi nedeniyle kuraklığa tolerans ıslahı açısından EDF, oldukça önemli bir parametre olarak kabul edilmektedir (Banziger ark. 2000). EDF değerinin düşük veya mümkünse hiç olmaması seleksiyonda tercih edilmektedir (Bolanos ve Edmeades, 1993; Edmeades ark. 1993; Byrne ark. 1995; Bolanos ve Edmeades 1996; Ribaut ark. 1997b; Ziyomo ve Bernardo, 2012). Bu nedenle Ant i-09, Ant i-69, Ant i-47 ve Ant i-24702 hatları bu özellik bakımından kuraklık stresine toleranslı genotipler olarak saptanmıştır. Diğer taraftan, kuraklık stresinden en çok etkilenen hatlar ise, Ant 910255, Ant i-08, Ant i82 ve Ant i-84 hatları olmuştur.

Normal (sulu) ve kuraklık denemelerine ait bitki başına koçan sayısına (BBKS) ilişkin iki yıllık analiz sonuçları Çizelge 3'te sunulmuştur. Önemli çıkan hat $x$ yıl interaksiyonu hatların sonuçlarının yıllara göre değiştiğini ortaya koymuştur. 2012 yılında normal denemede BBKS 0.5 adet (Ant 910255) ile 1.3 adet (Ant-24702) arasında değişmiştir. 2013 yılında BBKS değerleri 0.7 (Ant 910255 ve Ant i-82) ile 1.2 (Ant i-09 ve Ant i-98) arasında değişmiştir. 2012 yılında kuraklık denemesinde BBKS 0.1 adet (Ant i-08) ile 1.1 adet (Ant i-09) arasında değişirken, ortalama BBKS 0.5 adet olmuştur. 2013 yılında ise BBKS hatlarda 0.2 
adet (Ant 910255) ile 1.2 adet (Ant i-09) arasında değişmiş ve deneme ortalaması 0.7 adet olarak hesaplanmıştır. iki yıllık ortalama veriler değerlendirildiğinde, kuraklık stresi koşullarında en yüksek BBKS değerleri sırasıyla Ant i-09, Ant-24702 ve Ant i-69 hatlarından elde edilmiştir (Çizelge 3). Kuraklık stresinde bitki başına daha çok koçan yapabilen genotiplerin streslere daha toleranslı olduğu bilinmektedir (Baenziger ark. 2000; Bao- cheng ark. 2010). İki yıllık veriler incelendiğinde, bitki başına koçan sayısı bakımından Ant i-09 hattı her iki koşulda da üstün bir performans ortaya koyarak en başarılı hat olmuştur. Diğer taraftan, Ant i-69 hattı stres altında dahi normal koşullarla kıyaslandığında daha iyi performans göstererek kuraklık çalışmalarında kullanılabilecek genotiplerden birisidir.

Çizelge 2. Normal ve kuraklık denemelerinde hatlara ait erkek ve dişi çiçeklenme aralığı (gün)

\begin{tabular}{|c|c|c|c|c|c|c|c|c|}
\hline \multirow{3}{*}{$\begin{array}{l}\text { Hat adı } \\
\text { Ant-24698 }\end{array}$} & \multicolumn{4}{|c|}{ Normal deneme } & \multicolumn{4}{|c|}{ Kuraklık denemesi } \\
\hline & \multicolumn{2}{|c|}{2012} & \multicolumn{2}{|c|}{2013} & \multicolumn{2}{|c|}{2012} & \multicolumn{2}{|c|}{2013} \\
\hline & 3 & $\mathrm{~cd}$ & 2 & $a b$ & 2 & $\mathrm{~g}$ & 3 & $e-h$ \\
\hline Ant-24702 & 1 & g-I & 0 & fg & 2 & $\mathrm{~g}$ & 2 & hı \\
\hline Ant910255 & 3 & bc & 2 & bc & 8 & $a b$ & 8 & a \\
\hline Ant-i 05 & 3 & $\mathrm{~cd}$ & 2 & $a b$ & 6 & $c-f$ & 4 & c-e \\
\hline Ant-i 08 & 2 & e-g & 2 & $b-d$ & 9 & a & 3 & $d-g$ \\
\hline Ant-i 09 & 0 & 1 & 1 & $d-f$ & 0 & $\mathrm{~h}$ & 2 & I \\
\hline Ant-i 39 & 2 & de & 1 & c-e & 7 & $a-d$ & 2 & g-I \\
\hline Ant-i 42 & 1 & hı & 1 & e-g & 5 & ef & 2 & 1 \\
\hline Ant-ì 44 & 2 & de & 2 & $a b$ & 8 & $a-c$ & 3 & $d-g$ \\
\hline Ant-i 46 & 1 & $f-h$ & 1 & c-e & 5 & $d-f$ & 2 & hı \\
\hline Ant-i 47 & 1 & $f-h$ & 0 & $\mathrm{fg}$ & 2 & gh & 2 & hı \\
\hline Ant-i 69 & 2 & e-g & 1 & $d-f$ & 4 & $\mathrm{fg}$ & 0 & j \\
\hline Ant-i 81 & 2 & e-g & 2 & $a b$ & 6 & $c-e$ & 3 & $e-h$ \\
\hline Ant-i 82 & 2 & e-g & 3 & a & 8 & $a-c$ & 6 & $b$ \\
\hline Ant-i 84 & 4 & $a b$ & 2 & bc & 9 & a & 5 & $b$ \\
\hline Ant-i 89 & 3 & bc & 1 & $d-f$ & 6 & b-e & 4 & $\mathrm{~cd}$ \\
\hline Ant-i 98 & 4 & a & 2 & bc & 7 & $a-d$ & 4 & $\mathrm{~cd}$ \\
\hline TK 12 & 2 & $d-f$ & 2 & $a b$ & 6 & $c-f$ & 4 & $c-f$ \\
\hline TK 56 & 2 & $d-f$ & 1 & $c-e$ & 8 & $a-c$ & 3 & $f-I$ \\
\hline TK 72 & 2 & $d-f$ & 1 & c-e & 7 & b-e & 4 & $\mathrm{~cd}$ \\
\hline LSD & 0.8 & & 0.7 & & 2.1 & & & $7 * *$ \\
\hline VK (\%) & & & 28 & & & & & 26 \\
\hline Ort. & & & 1. & & 6 & & & 3 \\
\hline Hat x Yıl & & & & & & & & \\
\hline
\end{tabular}

**: \% 1 düzeyinde önemli

Normal (sulu) ve kuraklık denemelerine ait koçanda tane sayısına (KTS) ilişkin iki yıllık analiz sonuçları Çizelge 4'te sunulmuştur. 2012 yılında normal denemede KTS 58.6 adet (Ant i-98) ile 473.8 adet (TK 56) arasında değişmiştir. Deneme ortalaması ise 244.1 adet olmuştur. 2013 yılında KTS değerleri 315.8 adet (Ant I-98) ile 688.2 adet (TK 56) arasında değişirken, deneme ortalaması 2012 yılına göre daha yüksek olup 484.2 olarak hesaplanmıştır. İki yıllık sonuçlara göre normal koşullarda TK 56 ve TK 72 hatları en fazla KTS değerlerine sahip genotipler olmuşlardır. 2012 yılında kuraklık denemesinde KTS 8.7 adet (Ant I-98) ile 308.0 adet (TK 72) arasında değişirken, ortalama KTS 117.3 adet olmuştur. 2013 yılında ise KTS hatlarda 156.7 adet (Ant i-98) ile 557.8 adet (TK 56) arasında değişmiş ve deneme ortalaması 382.0 adet olarak hesaplanmıştır. íki yıllık ortalama veriler değerlendirildiğinde, kuraklık stresi koşullarında en yüksek KTS değerleri sırasıyla TK 72, Ant i-69, TK 12 ve TK 56 hatlarından elde edilmiştir (Çizelge 4). Schussler ve Westgate (1991) koçanda tane sayısının kuraklık stresinde düşmesinin temel nedenini fizyolojik düzeyde oluşan asimilat birikimi yetersizliğine bağlamışlardır. Bolanos ve Edmeades (1996) ve Khodarahmpour ve Hamidi (2014) stres altında tane verimi ile en fazla ilişkili özellik olarak koçanda tane sayısını bulmuşlardır. Bu nedenle, KTS bakımından kuraklık stresinde başarılı olan TK 72, Ant i-69, TK 56 ve TK 12 hatları, kuraklığa tolerans ıslahı açısından gelecek dönem çalışmaları için tavsiye edilebilir. 
Çizelge 3. Normal ve kuraklık denemelerinde hatlara ait bitki başına koçan sayısı değerleri (adet)

\begin{tabular}{|c|c|c|c|c|c|c|c|c|}
\hline \multirow{3}{*}{$\frac{\text { Hat adı }}{\text { Ant-24698 }}$} & \multicolumn{4}{|c|}{ Normal deneme } & \multicolumn{4}{|c|}{ Kuraklık denemesi } \\
\hline & \multicolumn{2}{|c|}{2012} & \multicolumn{2}{|c|}{2013} & \multicolumn{2}{|c|}{2012} & \multicolumn{2}{|c|}{2013} \\
\hline & 1.2 & $a b$ & 1.0 & b-e & 0.8 & $\mathrm{~cd}$ & 0.6 & ef \\
\hline Ant-24702 & 1.3 & $\mathrm{a}$ & 1.0 & $b-e$ & 0.9 & $b c$ & 0.9 & $b$ \\
\hline Ant910255 & 0.5 & $\mathrm{~h}$ & 0.7 & $\mathrm{~g}$ & 0.6 & ef & 0.2 & I \\
\hline Ant-i 05 & 1.1 & $a-c$ & 1.0 & b-e & 0.5 & $f$ & 0.8 & $b-d$ \\
\hline Ant-i 08 & 0.9 & $c-f$ & 1.0 & b-e & 0.1 & k & 0.6 & ef \\
\hline Ant-i 09 & 1.3 & $a$ & 1.2 & $a$ & 1.1 & a & 1.2 & a \\
\hline Ant-i 39 & 0.8 & $c-f$ & 0.9 & $d-f$ & 0.5 & fg & 0.9 & $b$ \\
\hline Ant-i 42 & 1.0 & $b-d$ & 1.0 & $b-d$ & 0.5 & $f-h$ & 0.7 & ef \\
\hline Ant-i 44 & 0.7 & e-h & 1.0 & $d-f$ & 0.3 & $h-j$ & 0.5 & $\mathrm{~h}$ \\
\hline Ant-i 46 & 0.9 & $b-e$ & 1.0 & $b-d$ & 0.2 & jk & 0.5 & gh \\
\hline Ant-i 47 & 0.9 & $c-f$ & 1.0 & b-e & 0.3 & $h-j$ & 0.6 & $\mathrm{fg}$ \\
\hline Ant-i 69 & 0.7 & $f-h$ & 0.9 & ef & 0.9 & $a b$ & 0.9 & bc \\
\hline Ant-i 81 & 0.8 & $d-f$ & 1.0 & $b-f$ & 0.3 & j & 0.9 & $b$ \\
\hline Ant-i 82 & 0.6 & gh & 0.7 & $\mathrm{~g}$ & 0.3 & $h-j$ & 0.4 & $\mathrm{~h}$ \\
\hline Ant-i 84 & 0.7 & $e-h$ & 0.9 & ef & 0.4 & g-I & 0.7 & ef \\
\hline Ant-i 89 & 0.9 & b-e & 1.0 & $c-f$ & 0.7 & de & 0.8 & c-e \\
\hline Ant-i 98 & 0.8 & $d-g$ & 1.2 & $a$ & 0.3 & Ik & 0.9 & $b-d$ \\
\hline TK 12 & 0.8 & $d-g$ & 1.1 & $a b$ & 0.5 & $f-h$ & 0.7 & $d-f$ \\
\hline TK 56 & 0.9 & $c-f$ & 1.1 & $a-c$ & 0.2 & jk & 0.6 & ef \\
\hline TK 72 & 0.8 & $\mathrm{~d}-\mathrm{g}$ & 1.0 & $c-f$ & 0.5 & $\mathrm{fg}$ & 0.9 & bc \\
\hline LSD & \multicolumn{2}{|c|}{$0.24^{* *}$} & \multicolumn{2}{|c|}{$0.11^{* *}$} & \multicolumn{2}{|c|}{$0.15^{* *}$} & \multicolumn{2}{|c|}{$0.15^{* *}$} \\
\hline VK (\%) & \multicolumn{2}{|c|}{17.3} & \multicolumn{2}{|c|}{7.09} & \multicolumn{2}{|c|}{19.02} & \multicolumn{2}{|c|}{12.21} \\
\hline Ort. & \multicolumn{2}{|c|}{0.9} & \multicolumn{2}{|c|}{1.0} & \multicolumn{2}{|c|}{0.5} & \multirow{2}{*}{\multicolumn{2}{|c|}{0.7}} \\
\hline Hat x Y II & & & & & & & & \\
\hline
\end{tabular}

**: \% 1 düzeyinde önemli

Normal (sulu) denemeye ait hatlarda yaprakta kuruma düzeyleri Şekil 2'de verilmiştir. Buna göre, I.dönemde hatlarda kuruma \% 10 ile \% 25 arasında değişmiştir. II. Dönemde olgunlaşma ile birlikte bu durum değişmiş ve kuruma düzeyleri hatlarda \% 12 ile \% 62 arasında değişmiştir. Dönemler arasındaki fark, olgunlaşma ile birlikte normal koşullarda yapraklarda kurumların arttığını göstermiştir. Ant-24698, Ant i-98 ve Ant i-69 hatları her iki dönemde de \% 20'nin altında kuruyarak diğer hatlara göre yeşil kalmışlardır. Diğer taraftan, II. Dönem gözlemlerine göre normal koşullarda Ant i08, Ant i-09, Ant i-42 ve Ant i-47 hatları en fazla kuruyan genotipler olmuşlardır.

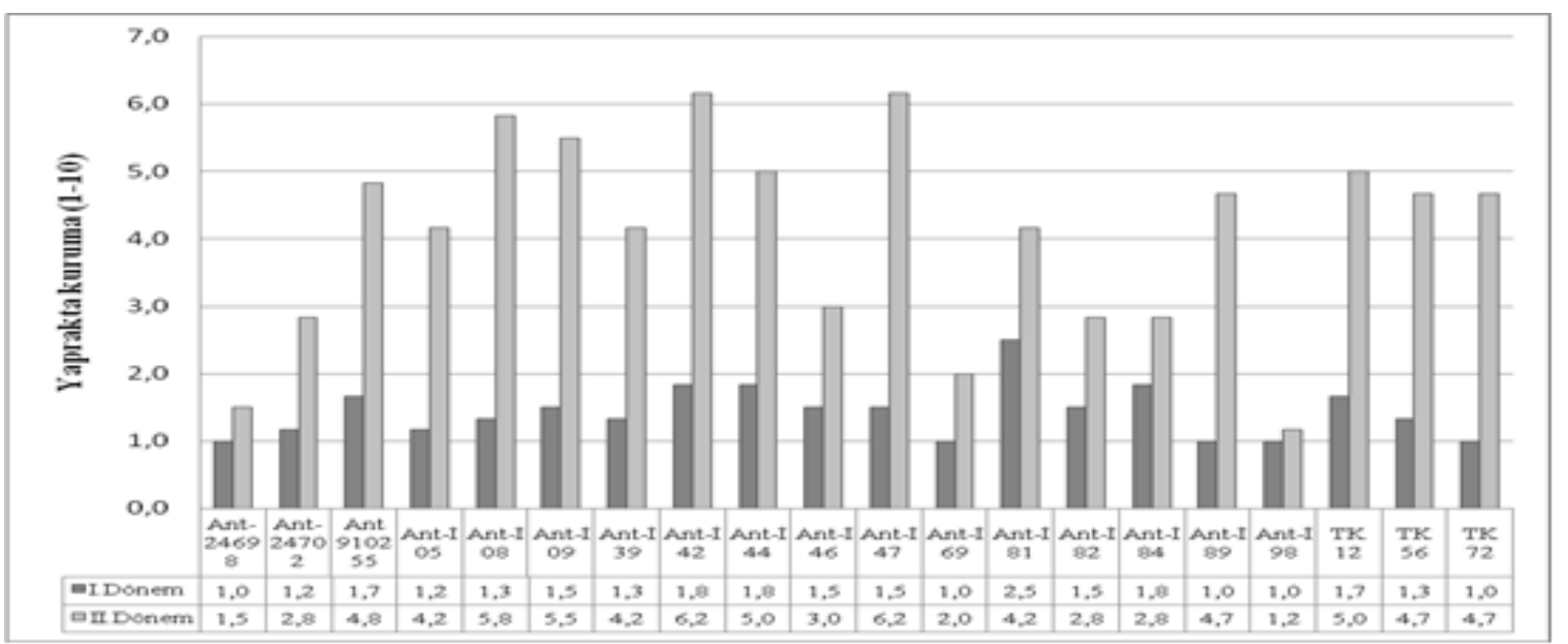

Şekil 2. Normal denemede hatlarda yaprakta kuruma düzeyleri ( $1=\% 10,2=\% 20,3=\% 30,4=\% 40,5=\% 50,6=\% 60$, $7=\% 70,8=\% 80,9=\% 90,10=\% 100$ ölü yaprak alanı (\%). 
Çizelge 4. Normal ve kuraklık denemelerinde koçanda tane sayısına ait değerler (adet)

\begin{tabular}{|c|c|c|c|c|c|c|c|c|}
\hline \multirow{3}{*}{$\begin{array}{l}\text { Hat adı } \\
\text { Ant-24698 }\end{array}$} & \multicolumn{4}{|c|}{ Normal deneme } & \multicolumn{4}{|c|}{ Kuraklık denemesi } \\
\hline & \multicolumn{2}{|c|}{2012} & \multicolumn{2}{|c|}{2013} & \multicolumn{2}{|c|}{2012} & \multicolumn{2}{|c|}{2013} \\
\hline & 282.8 & $\mathrm{bc}$ & 472.1 & c-e & 126.0 & $c-h$ & 261.2 & g-I \\
\hline Ant-24702 & 220.0 & de & 459.7 & $c-f$ & 144.1 & c-e & 403.0 & c-e \\
\hline Ant910255 & 210.6 & $d-f$ & 405.3 & $e-h$ & 26.6 & jk & 230.3 & hı \\
\hline Ant-i 05 & 265.3 & $b-d$ & 477.9 & $c-e$ & 106.3 & $f-h$ & 380.0 & $d-f$ \\
\hline Ant-i 08 & 287.4 & $b$ & 549.2 & $b-d$ & 203.9 & $\mathrm{~b}$ & 378.8 & $d-f$ \\
\hline Ant-i 09 & 162.7 & ef & 397.8 & $e-h$ & 91.1 & hı & 365.7 & $d-g$ \\
\hline Ant-i 39 & 264.9 & $b-d$ & 452.3 & $d-f$ & 100.1 & gh & 397.9 & c-e \\
\hline Ant-i 42 & 222.3 & $c-e$ & 443.3 & $d-g$ & 148.6 & $\mathrm{~cd}$ & 361.1 & $d-g$ \\
\hline Ant-i 44 & 155.5 & $f$ & 448.9 & $d-g$ & 22.1 & $\mathrm{k}$ & 317.6 & $e-h$ \\
\hline Ant-i 46 & 216.1 & $d-f$ & 485.2 & $c-e$ & 60.6 & ij & 346.2 & $d-g$ \\
\hline Ant-i 47 & 312.6 & $b$ & 491.9 & $c-e$ & 135.6 & $c-g$ & 439.2 & $b-d$ \\
\hline Ant-i 69 & 258.6 & $b-d$ & 563.1 & $\mathrm{bc}$ & 200.9 & $b$ & 499.7 & $a-c$ \\
\hline Ant-i 81 & 177.4 & ef & 358.3 & $f-h$ & 110.3 & $e-h$ & 348.7 & $d-g$ \\
\hline Ant-i 82 & 155.1 & $f$ & 344.0 & gh & 19.1 & k & 275.7 & $f-h$ \\
\hline Ant-i 84 & 254.6 & $b-d$ & 439.8 & e-g & 138.8 & $c-f$ & 449.1 & $a-d$ \\
\hline Ant-i 89 & 222.4 & $c-e$ & 688.0 & $a$ & 123.0 & $d-h$ & 502.8 & $a-c$ \\
\hline Ant-i 98 & 58.6 & g & 315.8 & $\mathrm{~h}$ & 8.7 & $\mathrm{k}$ & 156.7 & 1 \\
\hline TK 12 & 269.0 & $b-d$ & 550.1 & $b-d$ & 161.9 & c & 531.9 & $a b$ \\
\hline TK 56 & 473.8 & $a$ & 688.2 & $a$ & 119.0 & $d-h$ & 557.8 & $a$ \\
\hline TK 72 & 412.5 & a & 653.6 & $a b$ & 308.0 & $\mathrm{a}$ & 438.2 & $b-d$ \\
\hline LSD & \multicolumn{2}{|c|}{$62.09 * *$} & \multicolumn{2}{|c|}{$108.1^{* *}$} & \multicolumn{2}{|c|}{$37.01 * *$} & \multicolumn{2}{|c|}{$114.9 * *$} \\
\hline VK (\%) & \multicolumn{2}{|c|}{15.39} & \multicolumn{2}{|c|}{13.50} & \multicolumn{2}{|c|}{19.02} & \multicolumn{2}{|c|}{18.20} \\
\hline Ort. & \multicolumn{2}{|c|}{244.1} & \multicolumn{2}{|c|}{484.2} & & & \multirow{2}{*}{\multicolumn{2}{|c|}{382.0}} \\
\hline Hat x Yıl & & & & & & & & \\
\hline
\end{tabular}

**: \% 1 düzeyinde önemli

Kuraklık denemesine ait hatlarda yaprakta kuruma düzeyleri Şekil 3'te verilmiştir. Buna göre, I.dönemde hatlarda kuruma \% 12 ile \% 85 arasında değişmiştir. II. Dönemde kuraklığın etkisi daha fazla olmuş ve hatlarda kuruma düzeyleri \% 43 ile \% 100 arasında olmuştur. Ant i-69 hattı gerek I.dönem gerekse de II.dönem gözlemlerinde en fazla yeşil kalabilen genotip olmuş, bu hattı Ant-24698 ve Ant i-98 hatları takip etmiştir. Diğer taraftan koçan püskülü çıkışından 30 gün sonra (II.dönem) kuraklık stresi şartlarında tamamen kuruyan hatlar (Ant i-08, Ant $\mathrm{i}-46$ ve Ant $\mathrm{i}-81$ ) tespit edilmiştir.

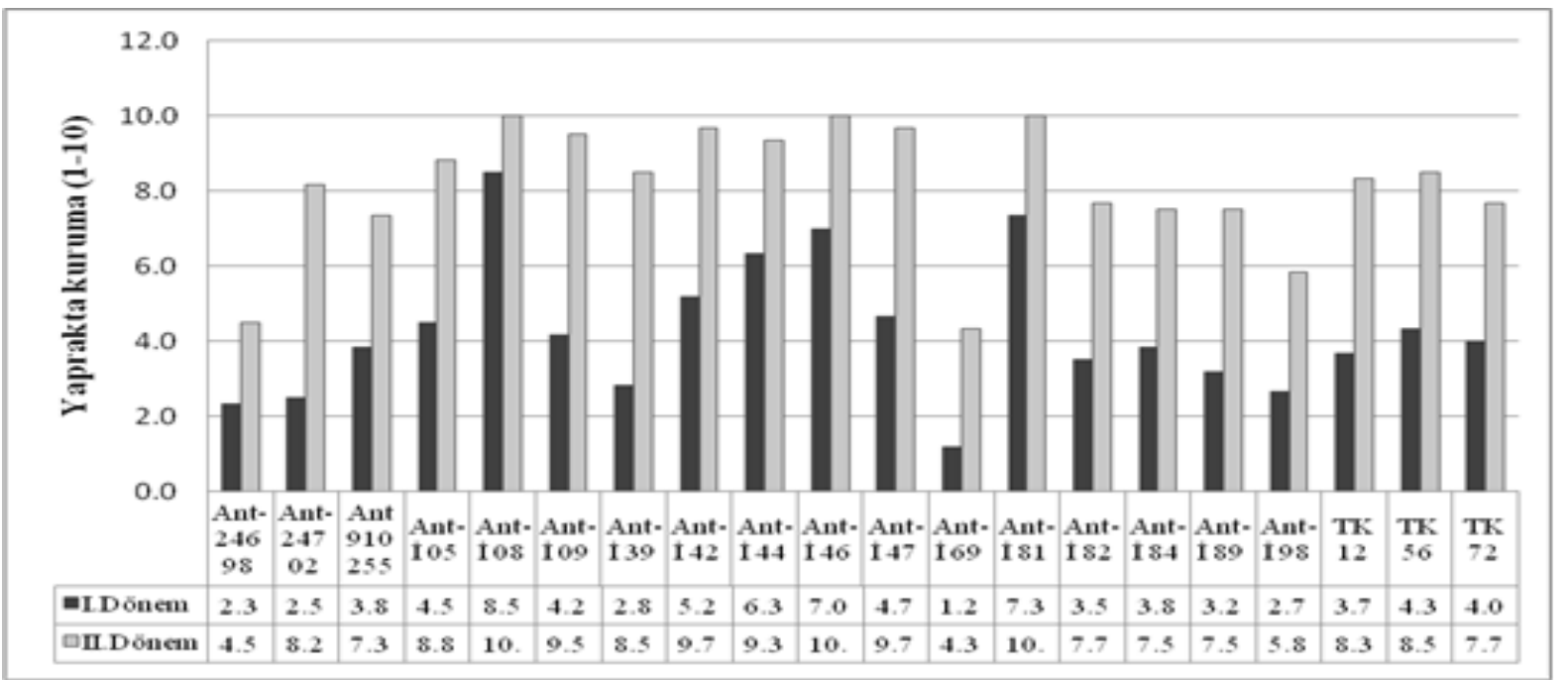

Şekil 3. Kuraklık denemesinde hatlarda yaprakta kuruma düzeyleri $(1=\% 10,2=\% 20,3=\% 30,4=\% 40,5=\% 50$, 6=\%60, 7=\%70, 8=\%80,9=\%90, 10=\%100 ölü yaprak alanı (\%). 
Orta düzeyde tane verimi ile olumlu ilişkisi ve orta düzeyde kalıtımı nedeniyle önemli olan yaprakta kuruma düzeyi gözlemlerinde, geç kuruyan (stay green) genotiplerin seçilmesinin kuraklığa tolerans ıslahı açısından önemli olduğu bildirilmektedir (Baenziger ark. 2000; Araus ark. 2012; Edmeades, 2013). Bu nedenle Ant i-69, Ant24698 ve Ant i-98 hatları yeşil kalma özellikleri nedeniyle bu özellik bakımından kuraklığa toleranslı hatlar olarak düşünülebilir. Normal ve kuraklık denemelerinden alınan ait tane verimleri $(\mathrm{kg} / \mathrm{da})$ Çizelge 5'te değerlendirilmiştir. Çizelge 5'e göre; 2012 yılında, normal denemede tane verimi 81.4 $\mathrm{kg} / \mathrm{da}$ (Ant i-98) ile $500.8 \mathrm{~kg} / \mathrm{da} / \mathrm{mm}$ (TK 72) arasında değişirken, deneme ortalaması 241.7 $\mathrm{kg} / \mathrm{da}$ olarak hesaplanmıştır. 2013 yılında ise hatlarda tane verimi değerleri $244.0 \mathrm{~kg} / \mathrm{da}$ (Ant i-82) ile 714.2 kg/da (TK 72) arasında değişmiştir. 2013 yılında deneme ortalaması $483.5 \mathrm{~kg} / \mathrm{da}$ olarak belirlenmiştir. 2012 yılında gerçekleşen yüksek sıcaklıklar, (Şekil 3.2 ve 3.3 ) özellikle tozlaşma dönemi sıcaklıkları, birçok verim ve verim komponenti üzerine etkili olmuştur. Buna karşılık
2013 yılında ise mısır yetiştiriciliği için optimum sıcaklıklar daha fazla yaşanmış, özellikle çiçeklenme dönemi sorunsuz atlatılmıştır. Her iki yıl arasında oluşan sözkonusu yüksek verim farklılıklarının iklim koşularından kaynaklandığı düşünülmüştür. İki yılık ortalama sonuçlar incelendiğinde TK 72 en verimli hat olurken bu hattı, TK 56 ve Ant-24702 hatları izlemiştir. Eski çalışmalarda hat verimi ile hibrit performansı arasında düşük korelasyon olduğu bildirilmektedir (Nilsson-Leissnerr, 1927; Jorgensen ve Brewbaker, 1927; Jenkins, 1929; Johnson ve Hayes, 1936; Hayes ve Johnson, 1939; Gama ve Hallauer, 1977). Ancak Vasal ark. (1999) farklı amaçlar için (biyotik, abiyotik stresler) hat performansının yoklama melezleri kadar önemli olduğunu ve son dönemlerde Uluslararası Buğday ve Mısır Geliştirme Merkezi (CIMMYT) mısır ıslah programlarında hat verim denemelerinin önemini vurgulamıştır. Araştırmamı ile normal koşullarda yüksek verim potansiyeli olan TK 72, TK 56 ve Ant24702 hatlarının gelecek dönem melezleme çalışmaları için kullanılabileceği öngörülmüştür.

Çizelge 5. Normal ve kuraklık denemelerinde hatlara ait tane verimi değerleri ( $\mathrm{kg} / \mathrm{da}$ )

\begin{tabular}{|c|c|c|c|c|c|c|c|c|}
\hline \multirow{3}{*}{$\begin{array}{l}\text { Hat adı } \\
\text { Ant-24698 }\end{array}$} & \multicolumn{4}{|c|}{ Normal deneme } & \multicolumn{4}{|c|}{ Kuraklık denemesi } \\
\hline & \multicolumn{2}{|c|}{2012} & \multicolumn{2}{|c|}{2013} & \multicolumn{2}{|c|}{2012} & \multicolumn{2}{|c|}{2013} \\
\hline & 394.2 & $\mathrm{~b}$ & 488.3 & de & 110.4 & $\mathrm{~cd}$ & 73.5 & $h-j$ \\
\hline Ant-24702 & 361.9 & bc & 614.1 & $\mathrm{bc}$ & 126.4 & bc & 266.3 & $a b$ \\
\hline Ant910255 & 169.9 & $h-j$ & 269.2 & $\mathrm{~h}$ & 20.2 & $k-m$ & 35.0 & j \\
\hline Ant-i 05 & 314.1 & $\mathrm{~cd}$ & 434.4 & e & 61.0 & fg & 110.1 & $f-h$ \\
\hline Ant-i 08 & 234.1 & $e-h$ & 476.8 & de & 8.8 & $\mathrm{~m}$ & 81.2 & $h-j$ \\
\hline Ant-i 09 & 192.7 & $h-j$ & 314.3 & gh & 99.8 & $d$ & 193.8 & $\mathrm{~cd}$ \\
\hline Ant-i 39 & 261.9 & $d-g$ & 569.6 & $\mathrm{~cd}$ & 72.3 & ef & 276.9 & a \\
\hline Ant-i 42 & 288.1 & $d-f$ & 624.4 & $a-c$ & 50.5 & $g-I$ & 170.5 & de \\
\hline Ant-i 44 & 98.6 & $\mathrm{kl}$ & 405.8 & e-g & 13.9 & $\mathrm{~m}$ & 84.5 & g-I \\
\hline Ant-i 46 & 160.7 & ık & 325.9 & $f-h$ & 12.8 & $\mathrm{~m}$ & 43.6 & ij \\
\hline Ant-i 47 & 228.6 & $f-h$ & 611.6 & $\mathrm{bc}$ & 35.9 & Ik & 130.2 & e-g \\
\hline Ant-i 69 & 171.7 & $h-j$ & 484.8 & de & 156.6 & a & 302.2 & $a$ \\
\hline Ant-i 81 & 198.2 & g-I & 444.4 & $\mathrm{e}$ & 31.6 & $j-1$ & 152.2 & $d-f$ \\
\hline Ant-i 82 & 132.5 & $j-1$ & 244.0 & $\mathrm{~h}$ & 16.6 & $\mathrm{Im}$ & 41.5 & ij \\
\hline Ant-i 84 & 200.5 & g-I & 499.2 & de & 42.8 & $h-j$ & 152.9 & $d-f$ \\
\hline Ant-i 89 & 149.8 & lk & 484.8 & de & 46.0 & $g-j$ & 175.9 & c-e \\
\hline Ant-i 98 & 81.4 & 1 & 420.1 & ef & 9.9 & $\mathrm{~m}$ & 84.0 & g-I \\
\hline TK 12 & 296.8 & c-e & 566.3 & $\mathrm{~cd}$ & 82.4 & e & 223.2 & bc \\
\hline TK 56 & 397.8 & $b$ & 678.3 & $a b$ & 55.0 & gh & 198.4 & $\mathrm{~cd}$ \\
\hline TK 72 & 500.8 & a & 714.2 & $a$ & 129.7 & $\mathrm{~b}$ & 311.3 & $a$ \\
\hline LSD & \multicolumn{2}{|c|}{$65.6^{* *}$} & \multicolumn{2}{|c|}{$95.1 * *$} & \multicolumn{2}{|c|}{$16.6^{* *}$} & \multicolumn{2}{|c|}{$47.5^{* *}$} \\
\hline VK (\%) & \multicolumn{2}{|c|}{16.43} & \multicolumn{2}{|c|}{11.89} & \multicolumn{2}{|c|}{17.20} & \multicolumn{2}{|c|}{18.20} \\
\hline Ort. & \multicolumn{2}{|c|}{241.7} & \multicolumn{2}{|c|}{483.5} & \multirow{2}{*}{\multicolumn{2}{|c|}{59.1}} & \multirow{2}{*}{\multicolumn{2}{|c|}{155.3}} \\
\hline Hat x Y.l & & & & & & & & \\
\hline
\end{tabular}

**: \% 1 düzeyinde önemli

2012 yılında kuraklık denemesinde hatlara ait tane verimleri $8.8 \mathrm{~kg} / \mathrm{da}$ (Ant i-08) ile $156.6 \mathrm{~kg} / \mathrm{da}$ (Ant i-69) arasında değişirken, deneme ortalaması
$59.1 \mathrm{~kg} / \mathrm{da}$ olmuştur. 2013 yılında ise tane verimi 35.0 kg/da (Ant 910255) ile 311.3 kg/da (TK 72) arasında değişmiştir. 2013 yılında kuraklık 
denemesinde ortalama tane verimi $155.3 \mathrm{~kg} / \mathrm{da}$ olarak hesaplanmıştır. İki yıllık ortalama sonuçlar ise kuraklık stresi şartlarında Ant i-69, TK 72 ve Ant24702 hatlarının en verimli genotipler olduğunu ortaya koymuştur. Kuchanur (2010) mısır saf hatlarını Hindistan ekolojik koşullarında kuraklık stresinde test etttiği araştırmasında normal ve kuraklık deneme ortalamalarını sırasıyla $426 \mathrm{~kg} / \mathrm{da}$ ve $132 \mathrm{~kg} / \mathrm{da}$ olarak tespit etmiştir. Khodarahmpour ve Hamidi (2014) İran şartlarında kendilenmiş mısır hatlarını kuraklık stresine tolerans açısından normal ve üç farklı gelişme dönemine göre taramıştır. Araştırmada normal koşullarda 275 kg/da tane verimi elde edilirken, çiçeklenme döneminde oluşturulan kuraklık şartlarında $166 \mathrm{~kg} /$ da ortalama tane verimi değeri elde edilmiştir. Aydınşakir ve ark. (2013) ise bir adet hibrit mısır (ŞAFAK) ve bir adet kendilenmiş mısır hattını (Ant i-90) farklı kısıntılı sulama koşullarında test etmiştir. Araştırmada tam su ve tam kurak konularında ŞAFAK çeşidi $935 \mathrm{~kg} / \mathrm{da}$ ve 363 kg/da verim verirken, Ant i-90 hattı tam su ve tam kurak konularda sırasıyla $743 \mathrm{~kg} / \mathrm{da}$ ve 144 $\mathrm{kg} / \mathrm{da}$ verim vermiştir. Genellikle kuraklık stresi şartlarında çalışmamızda olduğu gibi $200 \mathrm{~kg} / \mathrm{da}$ altında tane verimleri elde edilmiştir. Araştırmada verim performansları arasındaki farklar, genotipik farklılıktan, ekolojik şartlardan ve uygulanan kuraklık stres yönetiminden kaynaklanmaktadır. Araştırmada normal koşullarda TK 72, TK 56, Ant24702, Ant i-42, Ant-24698, Ant i-39, Ant i-47 ve TK 12 hatları $400 \mathrm{~kg} / \mathrm{da}$ üzerinde verim performansı olan hatlar olmuşlardır. Diğer taraftan iki yıllık kuraklık stresi şartlarında yürütülen deneme sonuçları ise Ant i-69 hattının en toleranslı hat olduğunu ortaya koymaktadır. Bu hattı TK 72, Ant24702 ve Ant i-39 hatları izlemiştir.

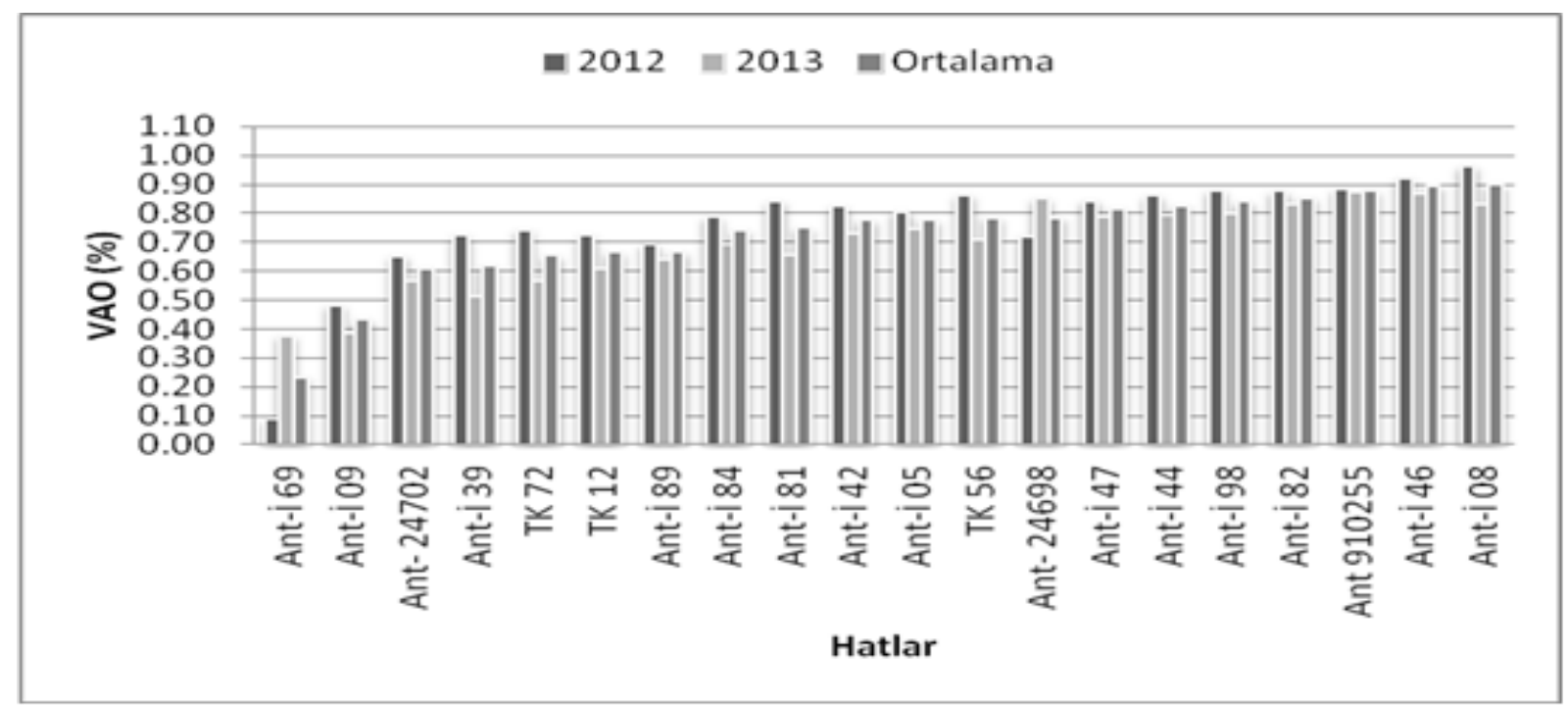

Şekil 4. Hatlara ait 2012, 2013 ve iki yıllık ortalama verim azalış oranları (\%).

Kuraklık stresinde en önemli seleksiyon kriteri olarak tane verimi kabul edilmekle birlikte kuraklık stresine toleranslılık, karmaşık kantitatif bir özellik olduğu için stress altında tane veriminin kalıtım ve genetik varyansı normal koşullara göre daha fazla düşmektedir (Baenziger ark. 2000). Bu nedenle bazı indeksler, hat/hibrit seleksiyonunda faydalı bilgiler verebilmektedir (Hao ark. 2011). VAO, bu indekslerden bir tanesi olup hatlarda kuraklık stresinden kaynaklanan verim kaybını ortaya koymuştur (Golestani ve Assad (1998). Şekil 4'te görüldüğü gibi Ant ì-69, Ant ì-09, Ant-24702, Ant i-39 ve TK 72 hatları kuraklık stresinden nispeten daha az etkilenen hatlar olurken, Ant i-08, Ant i-46, Ant 910255 ve Ant i-82 hatları ise en fazla etkilenen hatlar olmuşlardır.
Araştırmada önemli indekslerden olan kuraklılığa dayanıklılık indeksi (KDi) verileri Şekil 5'te gösterilmiştir.

Bir hattın yüksek KDi değeri aynı zamanda o hattın daha toleranslı olduğunu göstermektedir (Lan, 1998). Şekil 4.35'te görüldüğü gibi Ant i-69, Ant i-09, Ant-24702, Ant i-39 ve TK 72 hatları KDi indeksine göre toleranslı olan hatlardır.

Fernandez (1992) tarafından önerilen stres tolerans indeksi (STi) genel kabul görmüş indekslerden birisi olup, hem stres koşullarında ve hemde normal koşullarda verimli olan genotipleri ortaya çıkaran bir indekstir (Fernandez, 1992; Jafari ark. 2009; Hao ark. 2011). KDi indeksine benzer şekilde yüksek değerler daha yüksek toleranslılığı işaret etmektedir. Buna göre hatların 2012, 2013 ve iki yıllık ortalamalara göre aldıkları STi değerleri Şekil 6'da ise gösterilmiştir. 


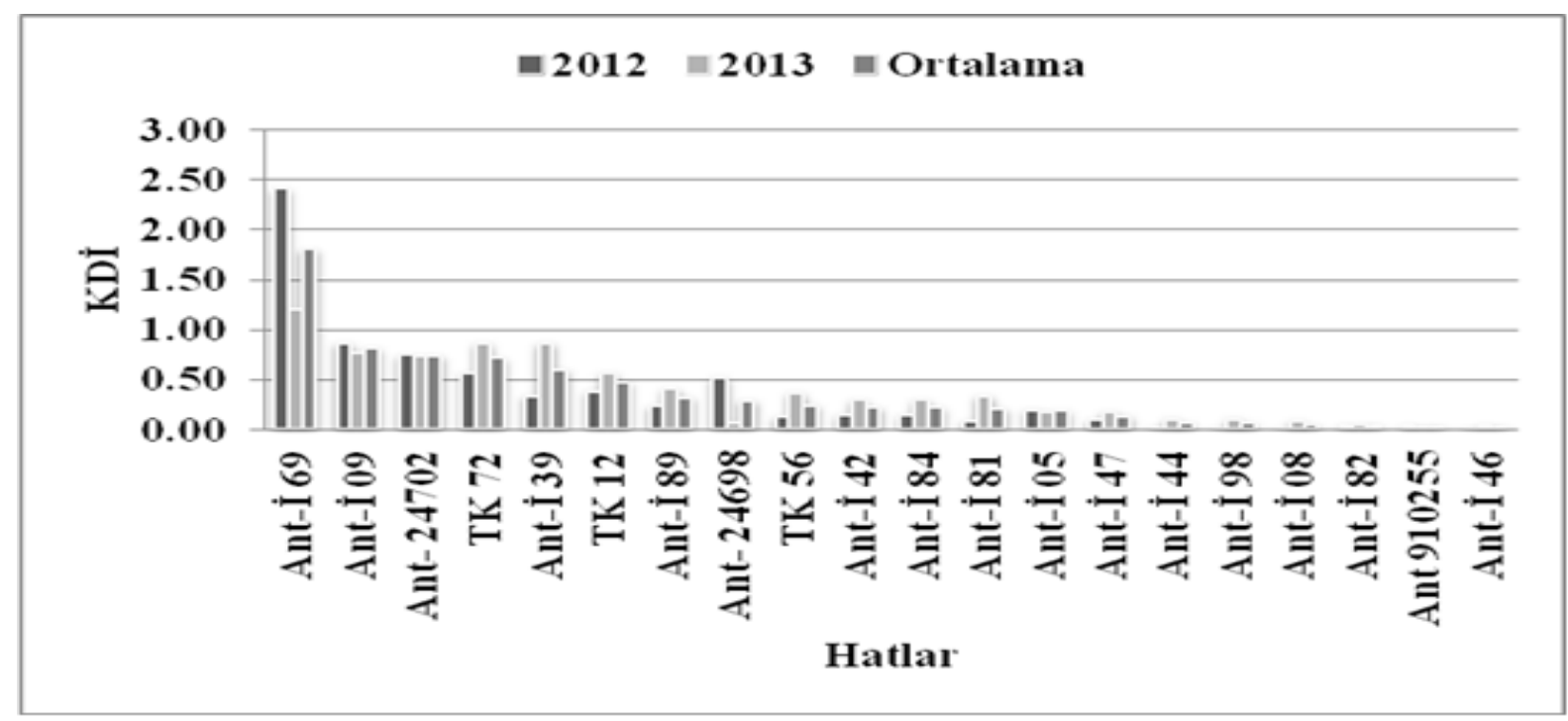

Şekil 5. Hatlara ait 2012, 2013 ve iki yıllık ortalama kuraklığa dayanıklılık indeksi sonuçları.

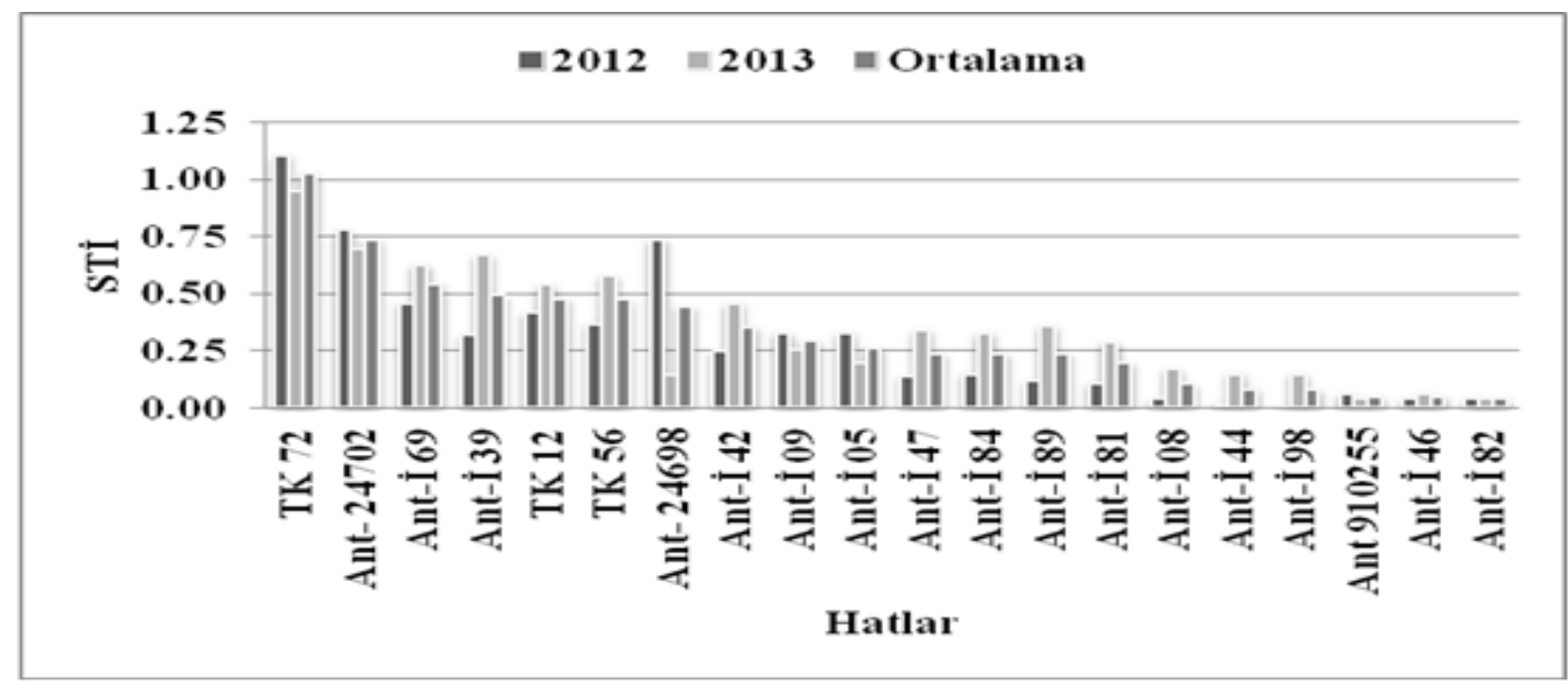

Şekil 6. Hatlara ait 2012, 2013 ve iki yıllık ortalama stres tolerans indeksi sonuçları.

Şekil 6'da görüldüğü gibi STi indeksine göre, TK 72, Ant-24702, Ant i-69 ve Ant i-39 hatları toleranslı hatlar olarak nitelenebilirken, en hassas hatlar ise Ant i-82, Ant 910255 ve Ant i-46 hatları olmuştur.

\section{Sonuç ve Öneriler}

Araştırma ile kendilenmiş mısır hatları normal (sulu) ve kuraklık koşulları altında test edilmiştir. Çalışma sonucunda, Ant i-69, TK 72, Ant24702, Ant i-39 ve Ant i-09 hatları kuraklık stresine en toleranslı hatlar olurken, Ant 910255, Ant i-46, Ant $\mathrm{i}-82$ ve Ant $\mathrm{i}-08$ hatları ise en hassas hatlar olmuşlardır. Belirtilen hatlar gelecek dönem melezleme programlarında yer alacaktır.
Teşekkür

\&: Bu çalışma, Süleyman Demirel Üniversitesi, Bilimsel Araştırma Projeleri Yönetim Birimi Başkanlığı 090-D-12 No'lu Projesi ile desteklenmiş ve Şekip Erdal'ın doktora tezinden hazırlanmıştır.

\section{Kaynaklar}

Akgöl, B. 2012. Pamukta (Gossypium hirsutum L.) Verim, Kalite ve Kuraklığa Dayanıklılık Özelliklerinin Kalıtımı. Tarla Bitkileri Ana Bilim Dalı, Doktora Tezi, Adana.

Araus, J.L., Serret, M.D., Edmeades, G.O. 2012. Phenotyping Maize for Adaptation to Drought. Frontiers Physiology, 3: 305.

Aydınşakir, K. Erdal, Ş. Büyüktaş, D., Baştuğ, R., Toker, R. 2013. The influence of regular deficit irrigation applications on water use, 
yield, and quality components of two corn (Zea mays L.) genotypes. Agricultural Water Management, 128: 65-71.

Banziger, M., Edmeades, G.O., Beck, D., Bellon, M. 2000. Breeding for Drought and Nitrogen Stress Tolerance in Maize, From Theory to Practice. Mexico, D.F.: CIMMYT.

Bao-cheng, S., Cheng L., Yun-su, S., Yan-chun, S., Tian-yu, W., Yu, L. 2010. Relationships Between Ear Number Per Plant and Drought Tolerance in Maize Hybrids. Xinjiang Agricultural Sciences, 2007-05.

Bolanos, J., Edmeades, G.O. 1993. Eight cycle of selection for drought tolerance in lowland tropical maize $2^{\text {nd }}$ responses in reproductive behavior. Field Crops Research, 31: 269-289.

Bolanos, J., Edmeades G.O., 1996. The Importance of the Anthesissilking Interval in Breeding for Drought Tolerance in Tropical Maize. Field Crops Research 48: 65-80.

Bruce, W.B., Edmeades, G.O., Barker, T.C., 2002. Molecular and Physiological Approaches to Maize Improvement for Drought Tolerance. Journal of Experimental Botany. 53, 13-25.

Byrne, P.F., Bolanos, J., Edmeades, G.O., Eaton, D.L., 1995. Gains from Selection under drought versus multilocation testing in related tropical maize populations. Crop Science, 35: 63-69.

Classen, M.M., Shaw, R.H. 1970. Water deficit effects on corn $2^{\text {nd }}$ grain components. Agronomy Journal, 62: 652-655.

Chocran, W.G., Cox, G.M. 1957. Experimental Designs. $2^{\text {nd }}$ Edn. John Wiley, New York, London and Sydney.

Das, B., Cairns, J.E., Atlin, G. 2013. Abiotic Stress Breeding: Currend Trends at CIMMYT. Korkut, K.Z., Eser, V., Başer, i. (Ed). Melez Mısırla Yüzyıl Çalıştayı (199-205), Ankara.

Denmead, O.T., Shaw, R.H. 1960. The effects of soil moisture stress at different stages of growth on the development and yield of corn. Agronomy Journal, 52: 272-274.

Edmeades, G.O. 2013. Progress in Achieving and Delivering Drought Tolerance in Maize - An Update, ISAAA: Ithaca, NY.

Edmeades, G.O., Banziger, M., Cortes, C.M., Ortega C.A. 1997. From Stress-tolerant Populations to Hybrids: The Role of Source Germplasm. pp. 263-273. In G.O. Edmeades et al. (ed.) Drought- Ribaut, J.-M., C. Jiang, D. Gonza'lezde-Leo' n, G.O. Edmeades, and and Low Ntolerant maize. Proceedings of a Symposium, El Batan.

Edmeades, G.O., Bolaños, J., Elings, A., Ribaut, J.M., Bänziger, M., Westgate, M.E. 2000. The Role and Regulation of the Anthesis-Silking Interval in Maize. p. 43-73. In: M.E. Westgate and K.J. Boote (eds.). Physiology and Modeling Kernel Set in Maize. CSSA Special Publication No. 29. CSSA, Madison, WI.

Edmeades, G.O., Bolaños, J., Hernandez, M., Bello, S. 1993. Causes for silk delay in a lowland tropical maize population. Crop Science, 33: 1029-1035.

Fernandez, G.C.J. 1992. Effective selection criteria for assessing plant stress tolerance. Proceeding of the International Symposium on Adaptation of Vegetables And Other Food Crops in Temperature and Water Stress, Aug. 13-16, Shanhua, Taiwan, pp. 257-270.

Gama, E.E.G., Hallauer, A.R. 1977. Relation between inbred and hybrid traits in maize. Crop Science, 17: 703-706.

Golestani, S.A., Assad, M.T. 1998. Evaluation of four screening techniques for drought resistance and their relationship to yield reduction ratio in wheat. Euphytica, 103: 293-299.

Grant, R.F., Jakson, B.S., Kiniry, J.R., Arkin, J.F. 1989. Water deficit timing effects on yield components in maize. Agronomy Journal, 81: 61-65.

Hao, Z.F., Li, X.H., Su, Z.J., Xie, C.X., Li, M.S., Liang, X.L., Weng, J.F., Zhang, D.G., Li L., Zhang, S.H. 2011. A proposed selection criterion for drought resistance across multiple environments in maize. Breeding Science. 61: 101-108.

Hayes, H.K., Johnson, I.J. 1939. The Breeding of improved selfed lines of corn. J.Am.Soc.Agron., 31: 710-724.

Jafari, A., Paknejad, F., Jami AL-Ahmadi, M. 2009. Evaluation of Selection indices for drought tolerance of corn (Zea mays L.) hybrids. International Journal of Plant Production 3(4): 33-38.

Jenkins, M.T., 1929. Correlation studies with inbred and crossbred strains of maize. J.Agric. Res., 39: 677-721.

Johnson, I.J and Hayes, H.K., 1936. The Combining Ability Of Inbred Lines Of Golden Bantam Sweet Corn. J.Am.Soc.Agron. 28: 246-252.

Jorgensen, L., Brewbaker, H.E. 1927. A Comparison of selfed lines of corn and first generation crosses between them. J.Am.Soc.Agron., 19: 819-830.

Karam, F., Breidy, J., Stephan, C., Rouphael, J. 2003. Evapotranspiration, Yield and water use efficiency of drip irrigated corn in the Bekaa Valley of Lebanon. Agricultural Water Management, 63: 125-137. 
Khodarahmpour, Z., Hamidi, J. 2014. Study of yield and yield components of corn (Zea mays L.) inbred lines to drought stress. Afr. J. Biotechnol., 11(13): 3099-3105.

Kırtok, Y. 1998. Mısır Üretimi ve Kullanımı. Kocaoluk Basım ve Yayınevi, Istanbul.

Kuchanur, H.P. 2010. Identification of Drought Tolerant Germplasm in Maize (Zea mays L.). Department of Genetics and Plant Breeding College of Agriculture, Dharwad University of Agricultural Sciences, Ph.D thesis, Dharwad.

Lan, J. 1998. Comparison of evaluating methods for agronomic drought resistance in crops. Acta Agriculturae Boreali-occidentalis Sinica, 7: 85-87.

Nilsson-Leissner, G. 1927. Relations of selfed strains of corn to $\mathrm{F} 1$ crosses between them. J.Am.Soc. Agron., 19: 440-451.

Öztürk, K. 2002. Küresel iklim değişikliği ve Türkiye'ye olası etkileri. G.Ü. Gazi Egitim Fakültesi Dergisi, 22(1): 47-65.

Pandey, R.K., Maranville, J. W., Admou, A. 2000. Deficit irrigation and nitrogen effects on maize in a Sahelion environment 1 . Grain Yield and Yield Components. Agricultural Water Management, 46: 1-13.

Peterson, R.G. 1994. Agricultural Field Experiments Design and Analysis. Marcel Dekker. Inc. 409 p.Corvallis. Oregon.USA.

Ribaut, J.M., Gonza'lez-de-Leon, D., Jiang, C., Edmeades, G.O., Hoisington, D.A. 1997a. Identification and Transfer of ASI Quantative Trait Loci (QTL): A Strategy to Improve Drought Tolerance in Maize Lines and Populations. In Edmeades, G.O., Banziger,
M., Mickelson, H.R., Pena-Valdiva, C.B. (eds). Developing Drought and Low N-Tolerant Maize. Proceedings of a Symposium, March, 25-29, CIMMYT, El Batan, Mexico.

Ribaut, J.M., Jiang, C., Gonza'lez-de-Leon, D., Edmeades, G.O., Hoisington, D.A. 1997b. identification of quantitative trait loci under drought conditions in tropical maize: I. yield components and marker-assisted selection strategies. Theor. Appl. Genet., 94: 887-896.

Schussler, J.R., Westgate, M.E. 1991. Kernel set of maize at low water potential: $2^{\text {nd }}$ Sensitivity to reduced assimilate supply at pollination. Crop Sci., 31: 1196-1203.

Türkeş, M., 1998. Influence of geopotential heights, cyclone frequency and southern oscillation on rainfall variations in Turkey. International Journal of Climatology, 18: 649-680.

UPOV, 2009. International Union for the Protection of New Varieties of Plants. www.upov.int.

Vasal, S.K., Sirinivasan, G., Cordova, H., Pandey, S., Jeffers, D., Bergvinson, D., Beck, D. 1999. Inbred line evolution nurseries and their role in maize breeding at CIMMYT. Maydica, 44: 341-351.

Viswanatha, G.B., Ramachandrappa, B.K., Nanjappa, H.V. 2002. Soil-plant water status and yield of sweet corn as influenced by drip irrigation and planting methods. Agricultural Water Management, 55: 85-91.

Ziyomo, C., Bernardo, R. 2012. Drought Tolerance in maize: Indirect selection through secondary traits versus genome wide selection. Crop Science, 53: 1269-1275. 